\title{
Phonological and orthographic factors in the word-superiority effect
}

\author{
GARVIN CHASTAIN \\ Boise State University, Boise, Idaho 83725
}

\begin{abstract}
Phonological and orthographic aspects of a letter string were found to affect the identification of a component letter in three experiments. All involved a fixed set of target vowels presented in a fixed position in letter strings. Manipulations of the phonological nature of the target or the orthographic character of the string were made by adding a letter with the postexposure mask to the original CVC trigram. In Experiment 1, the addition of an E with the mask as a final letter to the string changed the pronunciation of the target vowel, whereas the addition of an $\mathbf{S}$ did not. Identification accuracy was higher with the $\mathbf{S}$ mask. In Experiment 2, either E or D could be added to CVCs that were equally orthographic but differentially pronounceable. The same added letter had quite different effects on accuracy, depending on its effect on target pronunciation and the orthographic regularity of the string. In Experiment 3, performance on targets in orthographic CVCs was lowered to the level of nonorthographic CVCs by adding a letter that rendered the entire string nonorthographic. The results are explained by assuming that phonological and graphemic codes are developed simultaneously but maintained in a nonindependent manner.
\end{abstract}

A letter within a pronounceable string of letters can be more accurately identified than one within an unpronounceable string if the exposure is brief and followed by a patterned mask (Krueger, 1975a). The phenomenon is known as the word-superiority effect, and several explanations for it have been proposed. Johnston (1978) and McClelland and Johnston (1977) argue for the primacy of pronounceability itself. Their model assumes that individual letters in a string are more easily degraded while in a spatial format than as a pronounceable unit. Therefore, if possible, the string is encoded into such a unit to preserve the trace. Such units contain phonological sequences derived through the application of rules to combinations of letters that may be pronounced. Grapheme-to-phoneme correspondences have been developed and tested for letter sequences in various contexts (Gibson, Pick, Osser, \& Hammond, 1962). The tests have found that with tachistoscopic exposures, sequences that conform to the correspondence rules are more accurately reported. Other studies have shown that orthographic, pronounceable letter strings are more perceptible than strings of unrelated letters (Baron \& Thurston, 1973; Gibson, Shurcliff, \& Yonas, 1970). However, since the pronounceability and orthographic "legality" of a string are usually confounded, an independent evaluation of the former is often difficult.

With the forced-choice procedure typically used to demonstrate the word-superiority effect, many studies have found a small but reliable advantage of words over

I would like to thank two anonymous reviewers for their helpful comments regarding an earlier version of the manuscript. Requests for reprints should be sent to Garvin Chastain, Department of Psychology, Boise State University, Boise, Idaho 83725. orthographic pseudowords (Juola, Leavitt, \& Choe, 1974; McClelland, 1976; Spoehr \& Smith, 1975, Experiment 1). Manelis (1974) also found the identification of words to be more accurate than the identification of orthographic pseudowords. However, his subjects also rated the words as more pronounceable than the pseudowords. Perhaps words have obtained their advantage over pseudowords in other studies for the same reason.

Pronunciation has been shown to affect identification accuracy apart from orthographic regularity. Spoehr and Smith (1973) found that two-syllable words were identified less well than were one-syllable words of the same length. Krueger (1975b) presented words and nonwords either in the left visual field (projected to the usually nonverbal right hemisphere) or the right visual field (projected to the usually verbal left hemisphere). Letter identification was better in words only in the right visual field, suggesting that the word-superiority effect has a verbal basis rather than a spatial one. Krueger and Shapiro (1979) found that silent letters, such as the $\mathrm{H}$ in SLIGHT or the $\mathrm{E}$ in CLOTHE, were very difficult to identify in words. Finally, Purcell, Stanovich, and Spector (1978) used a fixed set of three-letter stimuli in which the position of the target was known in advance. With either two or four possible targets and with words mixed in a block with nonwords, a marked wordsuperiority effect was observed when the strings subtended a visual angle of less than $1 \mathrm{deg}$. When the same letters were spread to subtend a visual angle slightly over $2 \mathrm{deg}$, the word superiority was eliminated. While the possibility has arisen that the results observed by Purcell et al. were at least partly due to differential lateral masking between the word and nonword strings (Paap \& Newsome, 1980), widely spaced letters may be 
difficult to encode into a single phonological unit rather than as different single letters.

Another explanation of the word-superiority effect appeals to the use of visual aspects of orthographic letter strings that are not present in unrelated strings of letters. In this view, the phonological code does not provide the basis for the effect. Support for the purely graphemic model was reported by Baron and Thurston (1973), who found that recognition of a probe alterna. tive was as accurate with homophones (e.g., FOURFORE) as with nonhomophones (e.g., SOUR-SORE). If the comparison has been made on the basis of a phonological code, performance on homophones should have been poorer than that on nonhomophones. Likewise, Pollatsek, Well, and Schindler (1975) found that latency to respond "different" to homophonic word pairs was no longer than latency to respond to nonhomophonic word pairs. Singer (1980), using artificial letters to represent orthographic and nonorthographic strings, imposed response deadlines and found that visual information preceded phonological information in the recognition of the pseudoword targets.

Finally, some evidence indicates that subjects may optimize their performance by using either a phonological or a graphemic code, as the situation requires. Hawkins, Reicher, Rogers, and Peterson (1976) had subjects indicate which of two alternative words had appeared. When the proportion of homophones in the stimulus list was low (18 of 224 items), performance was better on nonhomophones than on homophones. However, when the proportion of homophones was increased approximately sixfold, homophones were recognized as well as nonhomophones were. Spoehr (1978) followed her presentations with either a blank field or a pattern mask that was designed to interfere more with a visual than with a phonological processing strategy. Letter strings were all orthographic, but they varied in phonological complexity. Consonant with her predictions, accuracy of identification of a target letter varied inversely with string complexity on presentations followed by the pattern mask but was invariant with complexity on presentations followed by the blank field. Subjects apparently altered their processing strategy according to the nature of the postexposure field.

While alternative processing strategies may be possible, both visual and verbal encoding may proceed simultaneously in a manner somewhat analogous to Paivio's $(1975,1978)$ dual coding hypothesis. Subjects may then be able to select the code that serves to maximize accuracy. However, the codes may not be maintained in a strictly independent manner, so that interference with one code would produce interference with the other. Indeed, the very coexistence of two such codes might be demonstrated by producing instances of such interference.

The experiments to be described in the current study were conducted to determine the relatedness of phonological and orthographic formats in the storage of letter strings. Common to all the experiments is the technique of presenting a terminal letter with the postexposure mask, which either alters the pronunciation of the target vowel or destroys orthographic "legality" when added to the string containing the target. The target to be identified always appeared in the middle position of the three-letter string presented initially. Taken together, the experiments indicate that both the graphemic and phonological nature of the target are influenced by context letters to produce the word-superiority effect.

\section{EXPERIMENT 1}

McClelland and Johnston (1977) argue that since letters existing in a spatial format are subject to rapid degradation, viewers transform them into a more stable phonological code when possible. If so, the phonological code might be disrupted when information that suddenly alters the pronunciation of the target appear. Fries (1963) has noted that the pronunciation of the vowel in certain three-letter strings is altered when an $E$ is added to follow the final consonant (tin becomes tine, pan becomes pane, for example). In the currect experiment, the vowel within various $\mathrm{CVCs}$ was made the target under brief exposure conditions. The postexposure mask contained three masking characters superimposing the letter positions in the stimulus array; in addition, either the letter $\mathrm{E}$ or the letter $\mathrm{S}$ followed the rightmost masking character (see Figure 1). The later addition of an $E$ to some sequences changes the pronunciation of the target, whereas the addition of a different letter, for example, $\mathrm{S}$, does not. However, the addition of either $\mathrm{E}$ or $\mathrm{S}$ results in an orthographic letter string (see Table 1). If subjects can attend only to the orthographic aspects of the string in identifying the target, equal accuracy would be expected with the addition of $E$ and S.

If the phonological code for the target letter exists or is being developed at the time of the appearance of the mask, perhaps the mask containing the E would impair identification accuracy more than the mask containing the $S$ would, since the former alters the pronunciation of the target and the latter does not. This result would be quite consistent with the theory

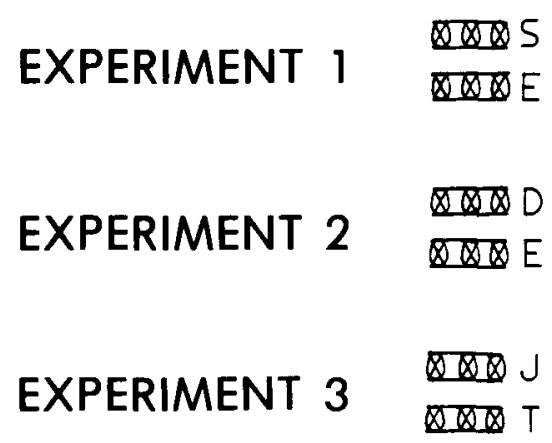

Figure 1. Masking arrays used in the three experiments. 
Table 1

Stimulus Strings and Suffixes from Masking Arrays Used in Experiment 1

\begin{tabular}{ccc}
\hline Column 1 & Column 2 & Column 3 \\
\hline CAR & CARS & CARE \\
CUR & CURS & CURE \\
BAN & BANS & BANE \\
BON & BONS & BONE \\
ROB & ROBS & ROBE \\
RUB & RUBS & RUBE \\
\hline
\end{tabular}

Note - Column $1=$ stimulus array; Column $2=$ stimulus array $+S$ suffix; Column 3 = stimulus array $+E$ suffix.

that a phonological code contributes to the wordsuperiority effect.

\section{Method}

Subjects. Eight students, four males and four females, served as subjects for extra credit in a general psychology course. Each reported normal or corrected-to-normal vision and participated in a single session lasting about $45 \mathrm{~min}$. All were naive concerning the experimental hypothesis.

Apparatus. Subjects self-triggered exposures for binocular viewing in a Scientific Prototype three-channel manual tachistoscope (Model $\mathrm{N}-1000$ ). The luminance of the continuously lit field was $10.00 \mathrm{~cd} / \mathrm{m}^{2}$, with the luminance of the stimulus field and the postexposure masking field set at $65.00 \mathrm{~cd} / \mathrm{m}^{2}$ and $40.00 \mathrm{~cd} / \mathrm{m}^{2}$, respectively. All luminances were measured with a Spectra Lumicon with Photospot attachment. The room was dimly illuminated by a shielded $40-\mathrm{W}$ bulb.

Stimuli. Three different target letters, always appearing between two letters in the stimulus array, were used: $A, O$, and U. Possible stimulus strings were CAR, CUR, BAN, BON, RUB, and ROB; hence each target letter appeared in two different strings. The strings subtended a visual angle of approximately $.82 \mathrm{deg}$. Masking arrays, which subtended a visual angle of $1.07 \mathrm{deg}$, were those shown for Experiment 1 in Figure 1. All characters were approximately $.28 \mathrm{deg}$ in height. The way in which the masking arrays affected the pronunciation of the target vowels may be seen in Table 1 . The mask containing the $S$ left the pronunciation of each target vowel unchanged from that in the three-letter stimulus array (Column 1 vs. Column 2). The mask containing the $\mathrm{E}$ altered the pronunciation of each target vowel (Column 1 vs. Column 3). A small black fixation dot appeared approximately $.2 \mathrm{deg}$ below the position of the target. Figures were traced in black ink with a Pilot Razor Point pen from a Berol Rapi Design lettering guide (R-2965) onto white index cards. The index cards were mounted on Masonite slides so that each masking character would completely overlap the corresponding stimulus character if both were shown simultaneously.

Experimental design. Each of the six three-letter strings was presented 16 times to each subject within the criterion series. Forty-eight practice trials, with each letter string appearing four times with each mask, preceded the criterion trials. The order of presentations was randomized for each subject, with the constraint that each letter string appear twice within each block of 12 trials, followed by each mask on one of these presentations.

Procedure. Each subject was first familiarized with the six strings and given their pronunciations. The pronunciation of each string with the letter in each mask added was then made explicit, although subjects were advised that the letter in the mask was irrelevant to the identification of the target. Subjects were told to report only the single letter above the fixation dot after each exposure, with a report required after each presenta- tion. The interstimulus interval was initially set at $95 \mathrm{msec}$ for each subject and was reduced to allow overall performance of about $75 \%$ during the first 48 trials. During the 96 criterion trials, the duration was adjusted only between blocks of 12 trials to maintain the subject's accuracy at about $75 \%$. The presentations proceeded in an uninterrupted series with an intertrial interval of about $5 \mathrm{sec}$. No feedback regarding accuracy was given, and subjects were unaware that only the last 96 presentations were criterion trials.

\section{Results and Discussion}

Mean accuracy with each of the three sets of flanking letters ( $\left.C \_R, B \_N, R \_B\right)$ within each masking condition was calculated for each subject. Performance on exposures followed by the mask containing the $\mathrm{E}$ (which changed the pronunciation of the target letter) was significantly poorer than that on trials presenting the mask containing the $S[F(1,7)=14.97, p<.01]$. Mean proportion of responses that were correct for presentations followed by the E mask was .734, and the mean for those followed by the S mask was .802 . The predominant pattern of performance was shown by seven of the eight subjects. Neither the effect of flanking letters nor the interaction of mask and flanking letters was significant (both ps $>.10$ ). An additional analysis comparing accuracy between target letters showed no main effect of letters and no interaction between target letters and masks (both ps $>.10$ ).

When masking array added a letter to the stimulus string that changed the pronunciation of the target letter, performance was poorer than when the added letter did not change the target's pronunciation. Apparently, the target was encoded in a phonological format; when additional information was introduced to change this code, accuracy suffered. However, the letters flanking the target were the same whether the presentation was concluded by the E mask or by the S mask. Therefore, only if the target's features combined in different ways with the mask's letter (although one letter intervened between the target letter and the mask's letter) could the effect be explained with reference to differential lateral masking. Such an argument appears difficult to maintain, particularly in the absence of any interaction between the mask variable and either flanking letters or target letters.

All strings that were produced with either letter from the mask were orthographic. If the graphemic code for the letters could be maintained separately from the phonological code, accuracy of target identification should not have differed with the masks. Of course, the current experiment did not actually test the wordsuperiority effect, since all letter strings were pronounceable.

Support for a phonological code that is not completely independent of a graphemic code would be much stronger if certain potential objections to the current experiment were addressed. Specifically, these objections are the following. 
(1) Subjects in the experiment were explicitly told what influence adding the letter with the mask to the original three-letter string would have on the pronunciation of the target. Perhaps this information produced demand characteristics that introduced an unnatural attempt to encode the target in relation to the letter in the mask. Omitting the pronunciation information might help insure that a more natural encoding was being made.

(2) The E with the mask changed the meaning of the original string, whereas the $S$ only changed the letter string from singular to plural. Perhaps part of the effect was due to semantic factor. With CAR, for example, the initial semantic representation would have to be modified only slightly to store CARS instead, whereas it would have to be entirely replaced to store CARE. Instead of using $S$, adding a letter with the mask that changes the meaning of the original string (as does $E$ ) would test this possibility.

(3) The E with the mask could have interfered with the target because both it and the target are vowels. In contrast, the $\mathbf{S}$ with the mask is a consonant and might not interfere as much with the target vowel. Choosing letter strings for which the vowel with the mask interferes more with the target vowel in some strings but the consonant with the mask interferes more in others would offer much stronger support for the hypothesis.

The objections mentioned above were treated in the following experiment.

\section{EXPERIMENT 2}

The preceding experiment suggests that a phonological code that is not maintained entirely separately from a graphemic code contributes to the wordsuperiority effect. The evidence might be more compelling if an actual superiority of words over nonwords was demonstrated as well. As in Experiment 1, a letter in the mask could be added to a CVC containing the target vowel; however, in some cases, the added letter would merely alter the pronunciation of the target, whereas in others, the added letter would produce a nonorthographic letter string.

The three-letter strings chosen for initial presentation in the current experiment are listed in Table 2, along with the changes produced by the addition of the terminal letters appearing with the masks (which are shown in Figure 1). The pronunciation of the $\mathrm{A}, \mathrm{O}$, or $\mathrm{U}$ target remains unchanged in the B_N strings with the addition of the $\mathrm{D}$ with the mask, although the meaning of the original string is changed. However, both target pronunciation and meaning of the string are changed with the addition of the $\mathrm{E}$ with the mask, which should impair performance. A completely different effect occurs with the S_S strings. The D with the mask renders the letter string orthographically impermissible, whereas the $\mathrm{E}$ maintains the string's orthographic
Table 2

Stimulus Strings and Suffixes from Masking Arrays Used in Experiment 2

\begin{tabular}{ccc}
\hline Column 1 & Column 2 & Column 3 \\
\hline BAN & BAND & BANE \\
BON & BOND & BONE \\
BUN & BUND & BUNE \\
SAS & SASD & SASE \\
SOS & SOSD & SOSE \\
SUS & SUSD & SUSE \\
\hline
\end{tabular}

Note-Column 1 =stimulus array; Column $2=$ stimulus array + D suffix; Column 3 = stimulus array $+E$ suffix.

characteristic. The addition of the $E$ to the $S \_S$ letter strings therefore should produce better performance. The overall word/pseudoword difference that is sometimes observed might emerge with these stimuli, since none of the S_S strings are words (with or without the letter in the mask), yet the B_N strings are words. In fact, the $E$ in the mask might not be expected to change the pronunciation of the target vowel within the S_S strings, since these strings were selected to be orthographic but of low pronounceability. Thus subjects viewing S_S strings followed by the E mask could use their orthographic nature as an aid to target identification without hindrance from the mask changing the target's pronunciation. If so, performance might be as good as that with the $B \_N$ strings followed by the $D$ mask.

Subjects were not given any pronunciation information in this experiment. If subjects perform as predicted, the results cannot be attributed to encouragement for integrating the letter with the mask with the letter string containing the target. Accordingly, if subjects perform differently on the string-mask combinations, as predicted, it will be obvious that the vowel $E$ with the mask sometimes interferes less with the target vowel than the consonant $D$ with the mask does.

Before the actual experiment, eight subjects (all psychology students) who were unfamiliar with the experiment were each given the 18 letter strings shown in Table 2 to rate for both pronounceability and orthographic regularity. Each string was typed on a separate index card, and half of the subjects made the pronounceability rating first. A rating scale from 1 to 10 was used for both ratings, with " 1 " indicating the lowest extreme. For the pronounceability rating, subjects were asked to rate the pronounceability of the letter string as a whole unit. For the orthographic rating, subjects were asked to indicate how well the string conformed to the rules for writing English, with consideration given to how permissible it was for each letter to follow the preceding one in an English word; ratings were not to be based on whether the letter string was an English word. These considerations were averaged into one rating for each letter string.

The results of the preliminary rating exercise appear in Table 3. Analysis of variance of these means for each subject found all main effects and interactions signifi- 
Table 3

Mean Ratings of Orthographic Regularity and Pronounceability Given Those Strings Appearing in Experiment 2

\begin{tabular}{|c|c|c|c|c|c|c|c|c|}
\hline \multirow{3}{*}{$\begin{array}{l}\text { Three- } \\
\text { Letter } \\
\text { String }\end{array}$} & \multicolumn{8}{|c|}{ Terminal Letter } \\
\hline & \multicolumn{2}{|c|}{ None } & \multicolumn{2}{|c|}{$\mathrm{D}$} & \multicolumn{2}{|c|}{$\mathrm{E}$} & \multicolumn{2}{|c|}{ Mean } \\
\hline & $\mathrm{O}$ & $\mathbf{P}$ & $\mathrm{O}$ & $\mathrm{P}$ & $\mathrm{O}$ & $P$ & $\mathrm{O}$ & $\mathbf{P}$ \\
\hline $\mathrm{B}_{-} \mathrm{N}$ & 9.7 & 9.8 & 8.5 & 9.3 & 9.6 & 8.4 & 9.3 & 9.2 \\
\hline$S \_S$ & 9.0 & 7.6 & 6.7 & 3.5 & 9.3 & 6.3 & 8.3 & 5.8 \\
\hline Mean & 9.4 & 8.7 & 7.6 & 6.4 & 9.5 & 7.4 & & \\
\hline
\end{tabular}

Note $-O=$ orthographic regularity; $P=$ pronounceability.

cant at the .05 level. A Duncan's new multiple-range test, which adjusts the size of the critical difference for all pairwise comparisons, was run. Despite this adjustment, it happened that all mean rating differences greater in magnitude than 1.7 were significant at the .05 level. The stimuli selected seem to have precisely those characteristics desired for the current experiment. The S_SD strings were judged to be significantly less orthographic than the other strings, with no significant differences among the other letter strings. Each $S \_S$ string was judged to be significantly less pronounceable than its corresponding $\mathrm{B} \quad \mathrm{N}$ string, with no significant differences emerging among the $\mathrm{B} \_\mathrm{N}$ strings on pronounceability. The S_SD strings were rated as significantly less pronounceable than the $S_{-} S$ and $S \_S E$ strings. Overall, the strings containing $\mathrm{B}$ and $\mathrm{N}$ were equally orthographic and pronounceable. The strings containing the Ss were, for the most part, as orthographic but not as pronounceable as those containing $\mathrm{B}$ and $\mathrm{N}$.

\section{Method}

Subjects. Seven males and eight females served as subjects. Their relevant characteristics were identical to those of subjects in Experiment 1. None had served as a subject before.

Apparatus. The apparatus and all its settings were identical to those in Experiment 1.

Stimuli. A, O, and U were the target letters. The target appeared as the middle letter in a three-letter string. Possible flanking letters were $B$ and $N$ and $S$ and $S$. The strings subtended a visual angle of approximately $.70 \mathrm{deg}$. Masking arrays, which subtended a visual angle of about $.94 \mathrm{deg}$, are shown for Experiment 2 in Figure 1. All characters subtended a vertical visual angle of about .21 deg. The ways in which the letter with the mask combined with those in the three-letter strings are shown in Table 2. The mask containing the $\mathrm{D}$ did not change the pronunciation of the target vowel from that in the original B..N strings, but it produced a nonorthographic string when added to the $S \_S$ strings. The mask containing the $E$ altered the pronunciation of the target in the $B_{-} \mathbf{N}$ strings, but it maintained the orthographic regularity of the $S_{-} S$ strings. All figures were prepared in the same manner as those in the preceding experiment, using the same lettering guide (which contains complete sets of characters in three different sizes).

Experimental design. Six different original three-letter strings were used, as in Experiment 1, and the design was identical to the one for that experiment.

Procedure. Each subject was initially shown each of the six three-letter strings alone and with each mask, but he or she was given no information regarding pronunciation or orthographic regularity. Subjects were instructed to report only the single letter above the fixation dot following each presentation. The other procedures were those used in Experiment 1.

\section{Results and Discussion}

Mean accuracy for each target letter with each pair of flanking letters within each masking condition was calculated for each subject. An analysis of variance indicated the expected significant interaction between flanking letters and masking condition $[\mathrm{F}(1,14)=10.54$, $\mathrm{p}<.01]$. Means for this interaction appear in Table 4. Student $t$ tests for correlated samples showed that the $D$ mask interfered significantly more than the $\mathrm{E}$ mask with target identification within the S_S strings [ $t(14)=$ $2.19, \mathrm{p}<.05]$. The even larger mean difference that indicated greater interference from the $E$ mask than from the D mask for targets within the B_N strings was also marginally significant $[\mathrm{t}(14)=1.85, \mathrm{p}<.10]$. Furthermore, an examination of the means from the nonsignificant Masking Conditions by Target Letters by Flanking Letters interaction revealed that for all targets, mean performance was better with the $D$ mask than with the $E$ mask for $B \_N$ strings, but worse with the $D$ mask than with the E mask for $S \mathrm{~S}$ strings $(\mathrm{p}<.02$ by a sign test).

Accuracy of identification of target letters did differ significantly $[F(2,28)=9.28, p<.001]$, and a significant interaction emerged between target letters and masks $[F(2,28)=6.57, p<.01]$. These effects are shown in Table 5. While the source of the performance difference between target letters could be that $\mathrm{O}$ and $\mathrm{U}$ are more similar to each other than either is to A, the explanation more likely relates to response bias. Analysis of responses given in error indicated that $46.8 \%$ of all erroneous responses were " $\mathrm{A}$ " (in contrast with $28.5 \%$ and $24.7 \%$ for " $O$ " and " $U$," respectively). In light of the very high performance on the $A$ targets, if $O$ and $U$ were merely being confused with each other, it seems that in the absence of response bias the lowest percentage of error responses would be "A." Only the 0 targets were identified significantly more poorly overall with the $D$ mask $[t(14)=2.44, p<.05]$, perhaps because of interference, since $O$ seems visually more similar to $D$ than does $A$ or

Table 4

Mean Proportion Correct for Targets Within Each Pair of Flanking Letters and Masking Condition in Experiment 2

\begin{tabular}{ccc}
\hline & \multicolumn{2}{c}{ Masking Condition } \\
Letters & $\mathrm{D}$ & $\mathrm{E}$ \\
\hline B_N & .761 & .700 \\
S_S & .686 & .745 \\
\hline
\end{tabular}

Table 5

Mean Proportion Correct for Target Letters Within Each Masking Condition in Experiment 2

\begin{tabular}{|c|c|c|c|}
\hline \multirow{2}{*}{$\begin{array}{l}\text { Target } \\
\text { Letter }\end{array}$} & \multicolumn{2}{|c|}{ Masking Condition } & \multirow[b]{2}{*}{ Mean } \\
\hline & $\mathrm{D}$ & $\mathrm{E}$ & \\
\hline $\mathbf{A}$ & .863 & .821 & .842 \\
\hline 0 & .642 & .754 & .698 \\
\hline $\mathbf{U}$ & .667 & .592 & .630 \\
\hline
\end{tabular}


U. No other main effect or interaction was significant (all Fs $<1.0$ ).

Following the experiment, each subject was asked whether he or she had organized the letter strings in some way to make the task easier. Thirteen of the 15 subjects mentioned that the original three-letter B_N strings were words, and 8 subjects made some reference to the way in which the letter with the masks combined to change the strings. None made specific comments regarding pronunciation, although five mentioned that the $D$ mask made identification easier with the B_N strings, and one of these subjects also said that the E mask helped in the S_S strings. More explicit questions were not asked for fear of leading subjects to make particular responses.

Results of the current experiment seem inconsistent with the possible explanations for the results of Experiment 1 that refer to artifactual nuisance variables. Although subjects were given no pronunciation information, they apparently integrated the letter with the mask with the stimulus strings. While both the $D$ and the E masks changed the meaning of the original B_N strings, only the $\mathrm{E}$ changed the pronunciation of the target vowel; this latter change was detrimental to target identification. Both masks combined with the B_N strings to produce orthographic strings, yet the effect on accuracy of the phonological change produced by the E mask was apparent. As in Experiment 1, it seems that the visual orthographic code can receive interference from the phonological code. However, the orthographic code appears useful to target identification in its own right. Performance was better with the S_SE strings than with the S_SD strings. Therefore, adding the $E$ (vowel) with the mask does not necessarily provide more interference with the target vowel than does adding a consonant with the mask. Instead, the orthographic characteristics of the entire four-letter combination must be considered.

One slightly bothersome aspect of the results from the current experiment is that a word-superiority effect was not observed. While the poorest overall mean performance did occur with the S_SD strings, it was not significantly poorer than performance with the B_NE strings $[t(14)=.41, p>.10]$. The following experiment was conducted to determine whether adding a terminal letter with the mask to an orthographically regular, pronounceable three-letter string to produce a nonorthographic, unpronounceable four-letter string would adversely affect target identification. Target identification in this case might be no better than with a string that was originally neither orthographic nor pronounceable.

\section{EXPERIMENT 3}

Results of the two foregoing experiments seem relevant to the word-superiority effect, although in neither experiment was a nonorthographic, unpro-
Table 6

Stimulus Strings and Suffixes from Masking Arrays Used in Experiment 3

\begin{tabular}{ccc}
\hline Column 1 & Column 2 & Column 3 \\
\hline PAN & PANT & PANJ \\
PEN & PENT & PENJ \\
PUN & PUNT & PUNJ \\
FAH & FAHT & FAHJ \\
FEH & FEHT & FEHJ \\
FUH & FUHT & FUHJ \\
\hline
\end{tabular}

Note-Column 1 = stimulus array; Column $2=$ stimulus array + $T$ suffix; Column 3 = stimulus array $+J$ suffix.

nounceable sequence presented as one of the original three-letter strings. In the current experiment, subjects were again attempting to identify a target as one of three possible vowels, but the target could be embedded initially in either an orthographic and pronounceable three-letter word or a nonorthographic, unpronounceable three-letter nonword. The terminal letter with the mask combined with these strings in the manner shown in Table 6. In only one case, the $P_{-} N \mathrm{~N}$ strings with the T mask, was the combined string orthographic and pronounceable. Performance in this situation was expected to be significantly better than with the other combinations. Equal accuracy was predicted with both masks for the F_H strings, since the letter with neither mask causes the original string to become either orthographic or pronounceable. Finally, adding a $\mathbf{J}$ from the mask to the $\mathrm{P} \_N$ strings produces a nonorthographic, unpronounceable four-letter string, which should lower performance to about the level observed with the F_HT and $F_{-} \_$HJ combinations. The predicted results would emphasize the fragile nature of the wordsuperiority effect and, again, show how it depends on information in the string other than that provided by those letters immediately flanking the target.

\section{Method}

Only two features distinguish the method in the current experiment from that in the second experiment. First, subjects were seven males and two females, whose relevant characteristics were identical to those of subjects in Experiments 1 and 2, although none had served before. Second, the target letters were $A, E$, and $U$, with flanking letters that combined with the letter with the masks as shown in Table 6. The masks appear in Figure 1. Stimuli were the same size and were prepared in the same manner as those in Experiment 2. The apparatus, experimental design, and procedures were identical to those for Experiment 2.

\section{Results and Discussion}

Mean accuracy for each target letter within each pair of flanking letters within each masking condition was calculated for each subject. An analysis of variance yielded significant main effects of target letter $[\mathrm{F}(2,16)$ $=9.00, \mathrm{p}<.01]$, flanking letters $[\mathrm{F}(1,8)=5.47, \mathrm{p}<.05]$, and masking condition $[F(1,8)=13.31, p<.01]$. The expected interaction of flanking letters and masking condition was significant $[F(1,8)=9.20, p<.02]$. The 
Table 7

Mean Proportion Correct for Targets Within Each Pair of Flanking Letters and Masking Condition in Experiment 3

\begin{tabular}{cccc}
\hline $\begin{array}{c}\text { Flanking } \\
\text { Letters }\end{array}$ & $\mathrm{T}$ & $\mathrm{J}$ & Mean \\
\hline P_N & .852 & .713 & .782 \\
F_H & .727 & .676 & .701 \\
Mean & .789 & .695 & \\
\hline
\end{tabular}

means for the main effect of target letter were: A, .695 ; $\mathrm{E}, .872 ; \mathrm{U}, .660$. Means for the significant main effects and interaction are shown in Table 7.

Response bias seems responsible for the significant difference in performance among target letters. Mean accuracy was higher for $\mathrm{E}$ targets, and, accordingly, $48.0 \%$ of all responses given in error were "E." In addition, there were no significant interactions with target letters.

The interaction between masking conditions and word/nonword three-letter strings was analyzed for the predicted relationship. As expected, no significant differences appeared between the $F_{\ldots} H_{J}$ and $F_{2}$ HT strings $[\mathrm{t}(8)=1.47, \mathrm{p}>.10]$ or between the P_NJ and $F_{-}$HJ strings $[t(8)=1.32, p>.10]$. Also in accordance with predictions, the $\mathrm{J}$ mask was much more damaging to performance than the $\mathrm{T}$ mask for the P_N strings $[t(8)=5.79, p<.001]$, and accuracy was higher with the T mask for the $P_{-} N$ strings than for the $F_{-}$H strings $[t(8)=3.24, p<.02]$.

When asked whether they had organized the letters in some helpful manner when performing the task, only four of the nine subjects mentioned that the $P \_N$ strings were words, and none mentioned the results of adding the letter with the masks to the original three-letter strings. Despite this fact, eight of the nine subjects performed better on the P_NT strings than on the P_NJ strings.

When the target appeared within the orthographic, pronounceable three-letter string $\left(\mathrm{P} \_\mathrm{N}\right)$, the addition of a terminal letter $\mathrm{J}$ from the mask produced relatively poor target identification. Yet, this addition did not actually change the pronunciation of the target letter. Nevertheless, performance was no better than that observed when targets had appeared within a nonorthographic, unpronounceable original three-letter string that was followed by the same terminal $\mathrm{J}$ from the mask. When the terminal letter from the mask was $T$, it was consistent with the orthographic nature of the original P_N string, and since the pronunciation of the target vowel was left unchanged, performance was relatively good. Of course, this same terminal $\mathrm{T}$ did not improve performance over that with a terminal $J$ when the original string was $\mathrm{F}_{-} \mathrm{H}$ and hence was neither orthographic nor pronounceable. The results of the current experiment relate the points regarding orthography and pronunciation made in the first two experiments more directly to the word-superiority effect.

\section{GENERAL DISCUSSION}

The three experiments just reported give evidence to indicate both an orthographic and a phonological component in the word-superiority effect. If a letter appearing after the original string containing the target continues the orthographic regularity of the string yet changes the pronunciation of the target, identification is poorer than if the added letter leaves both the orthographic regularity of the string and the pronunciation of the target intact. This effect occurs even if the added letter changes the meaning of the original letter string. The same additional letter may affect performance on different strings in the same list in different ways, depending on whether the addition changes target pronunciation or produces a nonorthographic string when combined with the original letters. Finally, performance on targets within a string that originally forms a word can be reduced to the level of performance on targets within nonword letter strings if an additional letter in the mask combines with the word to form a nonword. Through these observations, support was obtained for both a graphemic and a phonological code that can be used by observers attempting to identify a letter within a string of others. In addition, the graphemic and phonological codes apparently do not exist independently from each other. Adding a terminal letter with the postexposure mask that changes the pronunciation of the target without destroying the orthographic regularity of the letter string adversely affects target identification (Experiments 1 and 2). Likewise, if the added letter produces a nonorthographic letter string without changing the pronunciation of the target, target identification is adversely affected (Experiments 2 and 3 ).

In the current series of experiments, a fixed set of predesignated target letters appeared in a fixed, predesignated location in the letter strings. Striking effects on accuracy of target identification were produced without changing the letters immediately adjacent to the target; a terminal letter, appearing with the postexposure mask, was merely added to the original string. The final experiment revealed a word-superiority effect that was eliminated by introducing a terminal letter that converted the letter string as a whole into a nonword. The effects observed under the conditions described do not seem attributable to an explanation that has been offered frequently for the word-superiority effect. The basic premise of this explanation is that the identity of a target letter can be better inferred if it appears in a pronounceable string rather than among a string of unrelated letters (Massaro, 1973). Inferencebased explanations of the word-superiority effect are fundamentally sophisticated guessing models (Stanovich, 1979). Their basic assumption is that partial information gathered from a word context constrains the possible identity of a target letter more than does the same amount of information from a random string of letters. For example (after Massaro, 1973; see also Johnston, 1978), if a subject expects a pronounceable string and is 
presented SEP, on the basis of the information available the possibilities for the first letter might be narrowed to $\mathrm{S}$ or $\mathrm{B}$, for the second letter to $\mathrm{E}$ or $\mathrm{F}$, and for the third letter to $\mathrm{P}$ or R. Given these possibilities, the middle letter must be $\mathrm{E}$ for the string to be pronounceable, and the $\mathrm{E}$ will be selected accurately from the choices $\mathrm{E}$ and $O$. However, if only a random string of letters is expected, the middle letter may again be synthesized as $\mathrm{E}$ or $\mathrm{F}$. If the feature information is lost once the synthesis is complete and the $\mathrm{F}$ has been synthesized, the subject will guess randomly between the choices $E$ and $O$. A wide range of results has been interpreted as supporting the sophisticated guessing model (Bjork \& Estes, 1973; Rumelhart \& Siple, 1974; Thompson \& Massaro, 1973; Wheeler, 1970). Variants of the model exist, such as the one proposed recently by Paap and Newsome (1980), which claims that targets in words can be matched on the basis of fewer features than can targets in random strings because there is less confusion about target location in the former case. Recent evidence has seriously challenged the model. Johnston (1978) varied the strength of the constraining context around the target letter. Since the model attributes the word-superiority effect to constraints on the identity of the target exerted by the other letters, identification should be more accurate with a strongly constraining context. However, the target letter was no more likely to be identified correctly in a strongly constraining context (e.g., _RIP, for which the possibilities could be only $D, G$, and $T$ ) than in a weakly constraining one (e.g., _ATE, for which the possibilities are D, F, G, H, $\mathrm{L}, \mathrm{M}, \mathrm{P}, \mathrm{R}$, and $\mathrm{S}$ ). The findings that identification is not affected by the bigram or trigram frequencies within the word also seem inconsistent with the sophisticated guessing model (Chambers \& Forster, 1975; Manelis, 1974; McClelland \& Johnston, 1977). In the current series of experiments, subjects' knowledge of target alternatives could be used during the processing of the letter strings, and the knowledge would seem to eliminate any inference-based advantages in Experiment 3. More important, why would the addition of a terminal letter $\mathrm{J}$ in the mask destroy the sophisticated guessing advantage while the addition of a $T$ would not? A target letter may be identified better in words than in nonwords due to inferences, and this factor may have been involved in the word-superiority effect in many studies. However, the explanation does not seem applicable to the current results, and thus the wordsuperiority effect seems to occur without the benefit of sophisticated guessing.

Other explanations have advanced the notion that targets are recognized better in words than in random letter strings due to familiar supraletter features that are present in the former but not in the latter. If these features are processed simultaneously with letter features, this additional information would produce the wordsuperiority effect even if inferences were controlled. Variants of the model assume that readers can better resolve letter features in a word than in a nonword. Several recent studies have failed to show that word contexts provide this advantage. Massaro (1979) deleted varying amounts of the crossbar on a lowercase e, resulting in characters that were intermediate between an $e$ and a c. He found that the amount of the crossbar deleted was unrelated to the word vs. nonword context of presentation in the subjects' report of e or c. The word context evidently did not facilitate the detection of the amount of crossbar present. Accordingly, Krueger and Shapiro (1979) found that a mutilated A was detected no better in a word than in a nonword context.

A model recently has been proposed that seems able to account for a large number of findings involving the word-superiority effect (McClelland \& Rumelhart, Note 1; Rumelhart \& McClelland, Note 2). Introduced as the interactive activation model, it accounts for the better identification of a target letter in a word than in a nonword in terms of feedback occurring at several levels. Brief exposure of a word activates processing at a feature, letter, and word level. Activations at the word level feed back to the letter level, strengthening the activation of letters that spell the word. Target letters in a pronounceable nonword are assumed to gain their advantage over those in a string of unrelated letters through activating representations at the word level, although the pronounceable nonword does not perfectly match any word.

In the interactive activation model, the recognition units activated by feedback from the word level are both visual (graphemic) and phonological. The latter two interact with each other. Thus the present results may be consistent with the interactive activation model, although the nature of the grapheme-phoneme interaction in the model has not been elaborated. Nevertheless, the model would seem to predict that a terminal letter added after the offset of the string containing the target would have little effect on target identification. The effect of context is assumed to operate very early in the perceptual process. If contextual information appears before the target, it should prime the recognition unit for the target letter; however, contextual information appearing after the offset of the target should not have much effect on identification accuracy. The interactive activation model incorporates no provision for storage of the letter string while the target is being selected for output. With some extension to deal with the maintenance of the code for the letters, the model could accommodate the results of the current set of experiments.

\section{REFERENCE NOTES}

1. McClelland, J. L., \& Rumelhart, D. E. An interactive activation model of the effect of context in perception, Part 1 (Report No. 8002). San Diego: University of California, San Diego, Center for Human Information Processing, 1980.

2. Rumelhart, D. E., \& McClelland, J. L. An interactive activation model of the effect of context in perception, Part II (Report 
No. 8003). San Diego: University of California, San Diego, Center for Human Information Processing, 1980.

\section{REFERENCES}

Baron, J., \& Thurston, I. An analysis of the word-superiority effect. Cognitive Psychology, 1973, 4, 207-228.

BJork, E. L., \& Estes, W. K. Letter identification in relation to linguistic context and masking conditions. Memory \& Cognition, 1973, 1, 217-223.

Сhambers, S. M., \& Forster, K. I. Evidence for lexical access in a simultaneous matching task. Memory \& Cognition, 1975, 3, 549-559.

Fries, C. C. Linguistics and reading. New York: Holt, Rinehart, \& Winston, 1963.

Gibson, E. J., Pick, A., Osser, H., \& Hammond, M. The role of grapheme-phoneme correspondence in the perception of words. American Journal of Psychology, 1962, 75, 554-570.

Gibson, E. J., Shurcliff, A., \& Yonas, A. Utilization of spelling patterns by deaf and hearing subjects. In $\mathrm{H}$. Levin \& J. P. Williams (Eds.), Basic studies on reading. New York: Basic Books, 1970.

Hawkins, H. L., Reicher, G. M., Rogers, M., \& Peterson, L. Flexible coding in word recognition. Journal of Experimental Psychology: Human Perception and Performance, 1976, 2, 380-385.

Johnston, J. C. A test of the sophisticated guessing theory of word perception. Cognitive Psychology, 1978, 10, 123-153.

Juola, J. F., LeavitT, D. D., \& Choe, C. S. Letter identification in word, nonword, and single letter displays. Bulletin of the Psychonomic Society, 1974, 4, 178-180.

KRUEGER, L. E. Familiarity effects in visual information processing. Psychological Bulletin, 1975, 82, 949-974. (a)

Krueger, L. E. The word-superiority effect: Is its locus visualspatial or verbal? Bulletin of the Psychonomic Society, 1975 , 6, 465-468. (b)

Krueger, L. E., \& Shapiro, R. G. Letter detection with rapid serial visual presentation: Evidence against word superiority at feature extraction. Journal of Experimental Psychology: Human Perception and Performance, 1979, 5, 657-673.

Manelis, L. The effect of meaningfulness in tachistoscopic word perception. Perception \& Psychophysics, 1974, 16, 183-192.

Massaro, D. W. Perception of letters, words, and nonwords. Journal of Experimental Psychology, 1973, 100, 349-353.

Massaro, D. W. Letter information and orthographic context in word perception. Journal of Experimental Psychology: Human Perception and Performance, 1979, 5, 595-609.

MCClelland, J. L. Preliminary letter identification in the perception of words and nonwords. Journal of Experimental
Psychology: Human Perception and Performance, 1976, 2, 80-91.

MCClelland, J. L., \& Johnston, J. C. The role of familiar units in perception of words and nonwords. Perception \& Psychophysics, 1977, 22, 249-261.

PaAP, K. R., \& Newsome, S. L. Do small visual angles produce a word superiority effect or differential lateral masking? Memory \& Cognition, 1980, 8, 1-14.

Paivio, A. Perceptual comparisons through the mind's eye. Memory \& Cognition, 1975, 3, 635-647.

Paivio, A. Dual coding: Theoretical issues and empirical evidence. In J. M. Scandura \& C. J. Brainerd (Eds.), Structural/process models of complex human behavior. Leiden, The Netherlands: Nordhoff, 1978.

Pollatse K, A., Well, A. D., \& Schindler, R. M. Familiarity affects visual processing of words. Journal of Experimental Psychology: Human Perception and Performance, 1975, 1, 328-338.

Purcell, D. G., Stanovich, K. E., \& Spector, A. Visual angle and the word superiority effect. Memory \& Cognition, $1978,6,3-8$.

Rumelhart, D. E., \& Siple, P. Process of recognizing tachistoscopically presented words. Psychological Review, 1974, 81, 99-118.

Singer, M. H. The primacy of visual information in the analysis of letter strings. Perception \& Psychophysics, 1980, 27, 153-162.

Spothr, K. T. Phonological encoding in visual word recognition. Journal of Verbal Learning and Verbal behavior, 1978, 17, 127-141.

Spoenн, K. T., \& Sмiтн, E. E. The role of syllables in perceptual processing. Cognitive Psychology, 1973, 5, $71-89$.

Spoenr, K. T., \& Smith, E. E. The role of orthographic and phonotactic rules in perceiving letter patterns. Journal of Experimental Psychology: Human Perception and Performance, 1975, 1, 21-34.

Stanovich, K. E. Studies of letter identification using qualitative error analysis: Effects of speed stress, tachistoscopic presentation, and word context. Journal of Experimental Psychology: Human Perception and Performance, 1979, 5, 713-733.

Thompson, M. C., \& Massaro, D. W. Visual information and redundancy in reading. Journal of Experimental Psychology, $1973,98,49-54$.

Wheeler, D. D. Processes in word recognition. Cognitive Psychology, 1970, 1, 59-85.

(Revision accepted for publication December 2, 1980.) 